\title{
Estimation of Dispersion Phenomena for Selected Sites in Babylon Governorate
}

\author{
Abdulkareem H. Abed \\ Department of Applied Geology, College of Science, University of Babylon, Iraq. \\ abdalkreemrubaie@gmail.com
}

\begin{abstract}
This investigation is conducted to estimate the dispersion phenomena for selected sites in Babylon governorate (ALkheder - Almossiab, ALsadda, ALbunafaa, ALhashmia,).

The main aim of this investigation is to study dispersion phenomena, and identification and classification of soils to (high, intermediate, and non-dispersion) depending on special test methods in dispersion phenomena. The experimental tests that were done; indexes, physical, and chemical tests to natural soils and special tests were done to the identification and classification of dispersion soils.

The results of crumb test showed weak dispersion (Grade 2) for AL sadda soil, but the soils of ((ALkhezer - Almossaab, AL.bunafaa, AL.hashmia) showed intermediate dispersion (Grade 3).

The results of the double hydrometer test showed that ALkheder - Al.mossaab, and ALbunafaa were of intermediate dispersion soils, and for AL.hashmia, and AL sadda soils were non - dispersive.

The results of slacking test indicated that (ALkheder - Almossaab, ALbunafeej) were dispersive soils and (AL.hashmia, ALsadda soils) were non-dispersive.

While the results of soluble salts in pore water test indicated that all soils were non-dispersive but with different ratios according to its position in zone B of the classification chart.
\end{abstract}

Keywords: Babylon governorate, Crumb test, Dispersive soils, Double hydrometer test. 
Journal of University of Babylon for Engineering Sciences, Vol. (26), No. (7): 2018.

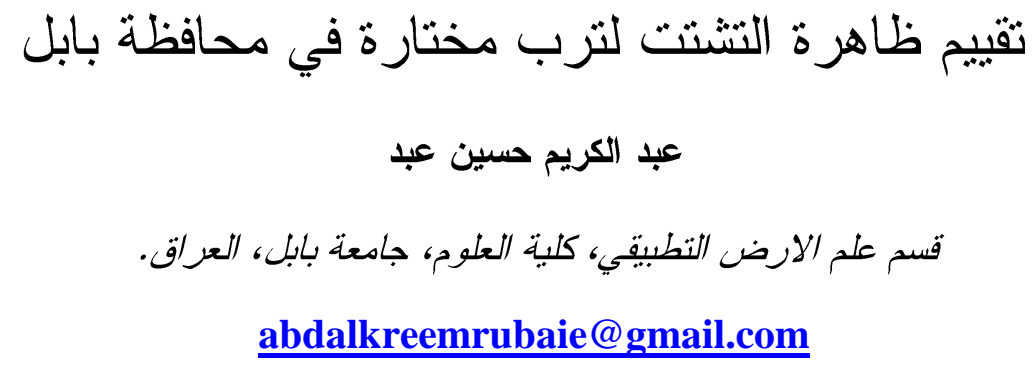

الخلاصة

يتتاول هذا البحث تقييم ظاهرة التشتت لترب مختارة من مناطق في محافظة بابل (المسيبب /الخضر،

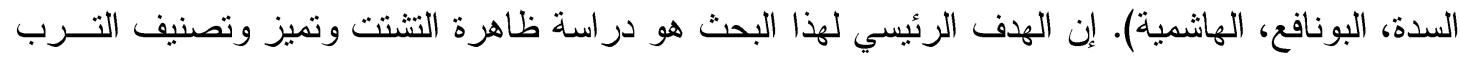
إلى (عالية التشتت، متوسطة التشتت، عديمة التشتت) اعتمادا على طرق الفحص الخاصة بظاهرة التشتت. أجريت الفحوصات المختبرية (الدليلية، الفيزيائية، الكيميائية) للترب الطبيعيــة، وكــللك الفحوصـــات الخاصة لتميز التزب المشتتة. فبينت نتائج فحص الفتاتة (Crumb test) هي ضعيفة التشتت (Grade 2) لتربة السدة، أما التـرب (Grade) (البونافع، المسيب /الخضر ، الهاشمية) فكانت متوسطة النتشت (Grade 3). و أظهرت نتائج فحص المكثاف المزدوج (The Double Hydrometer Test) إن التربتين (المسيب / الخضر ، البونافع) هي (Intermediate Dispersive، متوسطة النشتت) و التربتين (السدة، الهاشمية) كانت Non - Dispersive) ودلت نتائج فحص الركود (The Slackening Test) على ان التربتين (البونافع، الخضر) هي ترب مشتتة و التربتين (السدة، الهاشمية) كانت غير مشتتة. أما نتائج فحص الأملاح الذائبة في ماء المسام فأشنارت على إن الترب المستخدمة في البحث (المسيبي

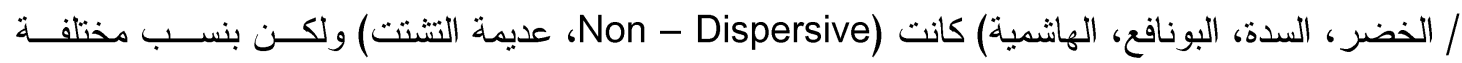
حسب موقعها بنطاق B في مخطط التصنيف. الكلمات المفتاحية: محافظة بابل، فحص الفتاتة، الترب المشتته، فحص للمكثاف المزدوج.

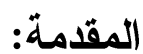
تعرف الترب المشتتة (Dispersive soil) بأنها الترب ذات التركيب غير المستقر، وذات مقاومة قليلة للتآكل، حيث تتداعى التربة المشتتة وتتهار عندما تحصل التزبة على رطوبة وبالتالي تتشتت جزيئات الطـينين في المحلول. ولكن الفرق الأساسي بين التزب المشتتة والتزب الغير المشتتة (المقاومة للتآكل) هو في طبيعة ونوع الايونات الموجودة في ماء المسام (water pour)، ففي الترب المشتتة تكون غالبية الايونات هي ايون الصوديوم، أما الترب غير المشتتة تكون أغلبية الايونات هي ايون الكالسيوم، المغنيسيوم[11].

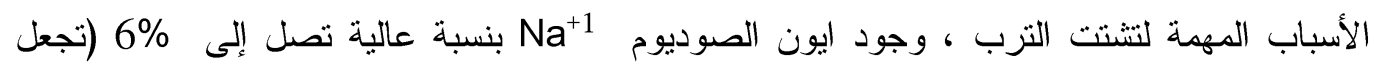
التربة غير مستقرة ) ، وكما هو معروف إن جزيئات الطين تملك شحنة سالبة على السطح ، هذه الثحنة

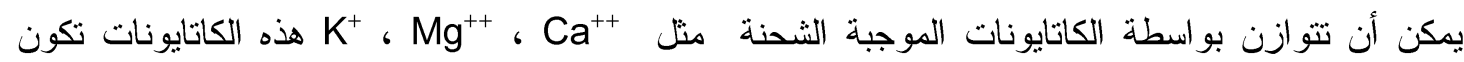

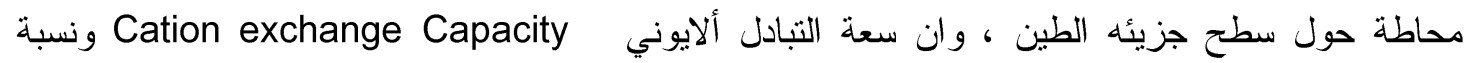


Journal of University of Babylon for Engineering Sciences, Vol. (26), No. (7): 2018.

الصوديوم Sodium percent لهما الأثر الأكبر في قابلية التشتت ، و علية فجزيئات الطين التي تقل فيها قوى التز ابط بالأخرى تكون سهلة التشتت عندما تصبح رطبة[2].

تتكون الترب المشتتة في الطبيعة، أما بتجوية الصخور الرسوبية إذ إن ايون الصوديوم ينتقل من

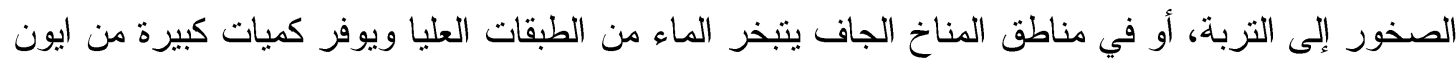

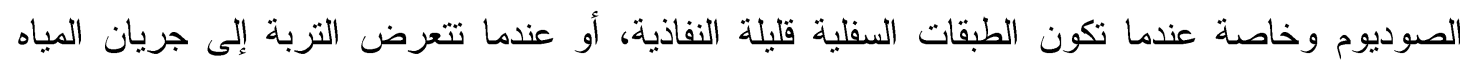
المالحة، أو كنتيجة لارتفاع أو انخفاض منسوب الماء الجوفي التي تزيد من محتوى ايونات الصوديوم في الطبقات العليا وبالتالي تتكون الترب المشتخة.

تتو اجد الترب المشتتة في الطبقات الغرينية وطبقات التربة المترسبة فـــ البحيــرات (Lacustrines)

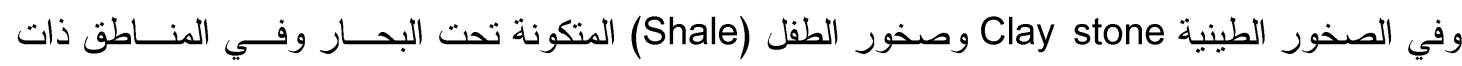

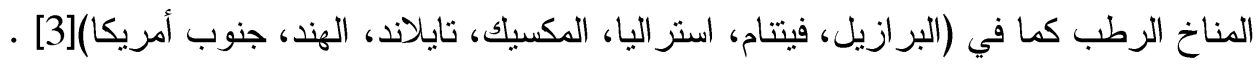
تسبب الترب المشتتة الكثير من المشاكل الهندسية ومنها انهيار العديد من السدود التزابية في الولايات

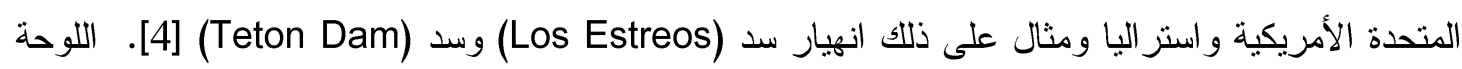

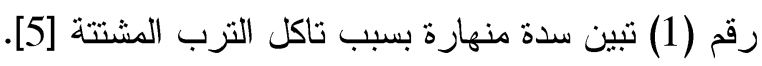

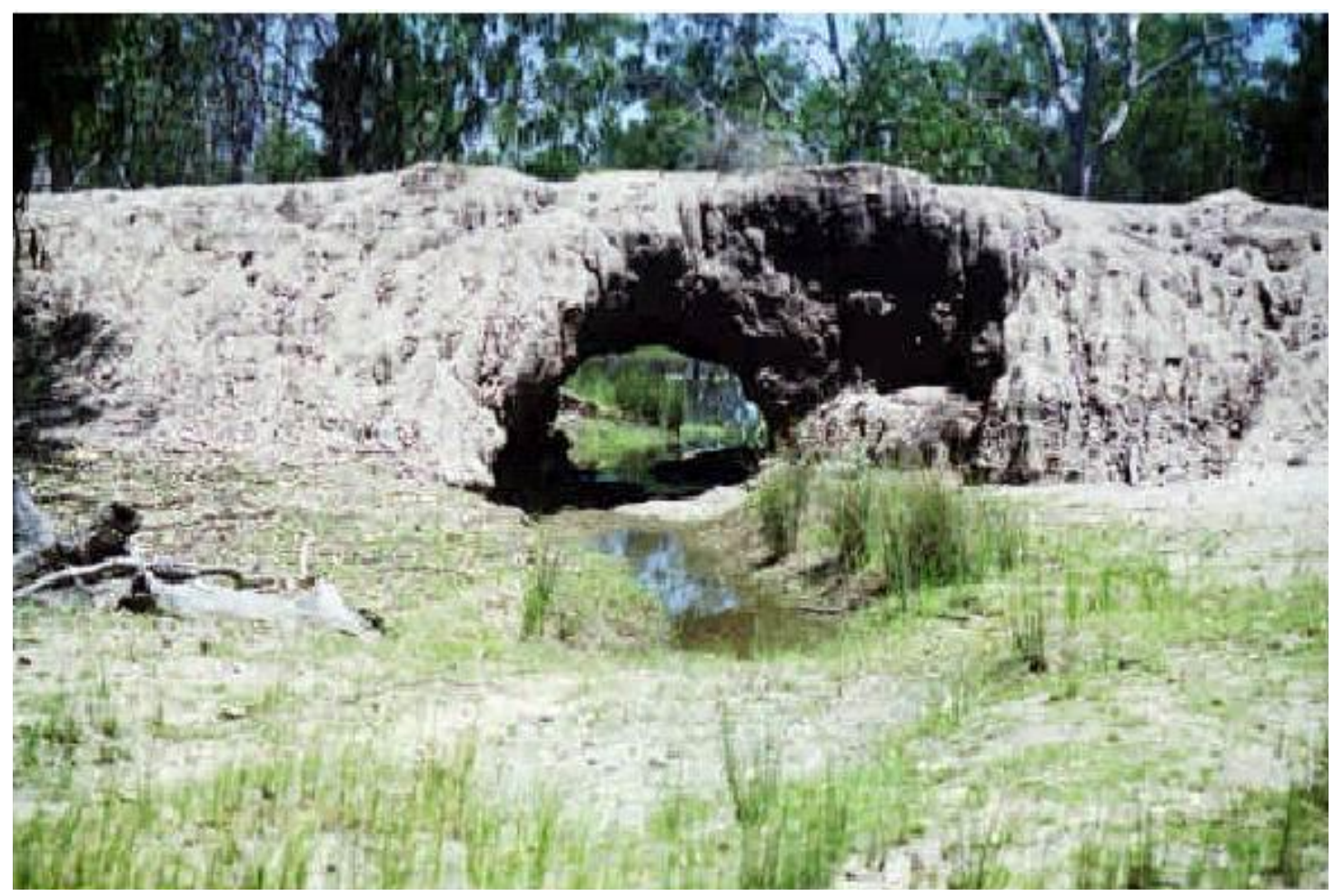

لوحة رقم (1) لسدة منهارة بسبب تآكل الترب المشتتة[5] . 
Journal of University of Babylon for Engineering Sciences, Vol. (26), No. (7): 2018.

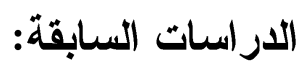

ومن الدراسات السابقة التي أرفدت هذا البحث منها

بين [6] تأثير المحتوى الرطوبي للترب المحدولة يكون واضح على معدل تآكل التربة التي لها دليل

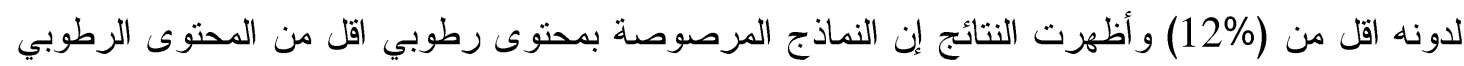

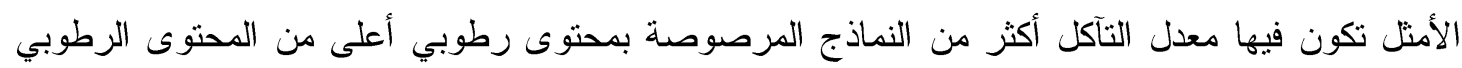

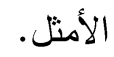

درس [7] التسرب التاكلي خلال التزب الجبسية والمعاملة بالنورة المطفأة، حيث جلب أربع نماذج تربة

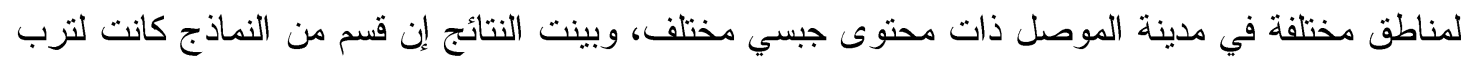

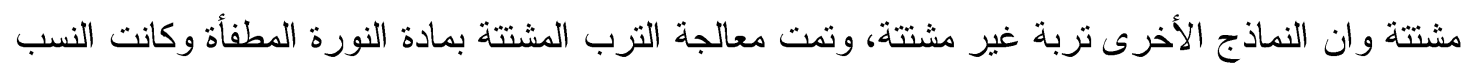
3\% و 5\% من النورة فعالة ومعالجة للنتشتت.

درس [8] آلية مقاومة التسرب الداخلي للترب غير المستقرة، حيث أخذت نماذج بصورة عثـو ائية

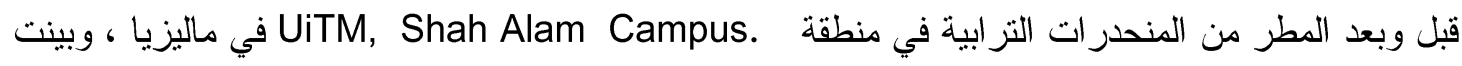

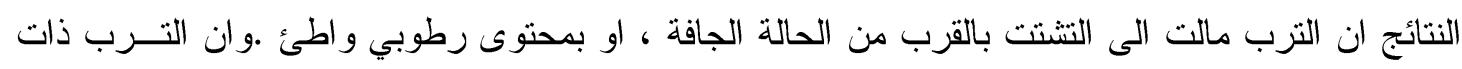
الحبييات الخشنة أعطت أعلى قيم للتشتت ، وهذا يدل على ان التزب ذابت ذات مقاومة تآكل و واطئة.

Materials and Experimental work

المواد والعمل ألمختبري

المواد المستخدمة:Materials

Soil التربة

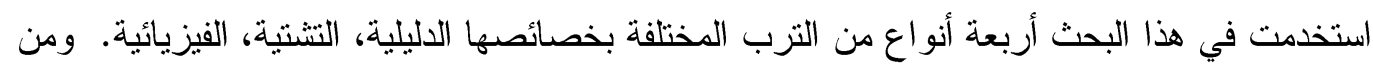
مو اقع مختلفة في محافظة بابل (السدة، المسيب/الخضر، البونافع، الهاثمية) من عمق تجاوز التزبة

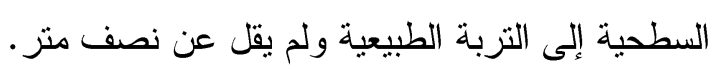

Water الماء

تم استعمال ماء الإسالة في جميع الفحوصات المختبرية التي أجريت في هذا البحث، كما واستعل الماء المقطر في بعض الفحوصات التي تستوجب استعماله.

Laboratory tests الفحوصات المختبرية:

تم إجر اء الفحوصات المختبرية لهذا البحث في مختبرات كلية العلوم /قسم علم الأرض التطبيقي، قسم الكيمياء /جامعة بابل. 
Journal of University of Babylon for Engineering Sciences, Vol. (26), No. (7): 2018.

Index properties and physical tests

Atterberg Limits
أولا: فحوصات الخواص الاليلية والفيزيائية 1

تم تعيين حدود اتربيرك (حد السيولة، حد اللدونة، دليل اللدونة) لجميع الترب حسب الطر ائق المعتمدة

من الجمعية الأمريكية للفحوص و المو اد [9].

Specific Gravity الوزن النوعي

تم تعين هذا الفحص للترب الطبيعية حسب الطريقة المتبعة في مواصفة الجمعية الامريكية للفحص و المو اد10]

Grain Size Analysis التحليل الحبيبي

تم إجر اء هذا الفحص حسب الطريقة المتبعة للفحوص و المواد [11].

4- فحص الرص Compaction test

نم إجراء فحص وتعين كل من الكثافة الجافة العظمى ومحتوى الرطوبة الأمثل باستعمال الطريقة المتبعة من الجمعية الأمريكية للفحص و المو اد [12].

Chemical tests انيا: الفحوصات الكيميائية 1-فحص محتوى الكبريتات Sulphate content tests

[13] Test - تم الفحص بموجب المو اصفة البريطانية (1377) لعام 1975 التي تحمل الرمز .Number -9-

Gypsum content tests فحص محتوى الجبس

$$
\text { يحسب الجبس بضرب نسبة الكبريتات للتربة * 2.15\% }
$$

3- فحص محتوى الأملاح الكلية القابلة للذوبان Total soluble salts Test

تم إيجاد مقدار الأملاح القابلة للذوبان للتربة الطبيعية بالاعتماد على الطريقة المذكورة في Earth ASTM. في ال manual 4H value بحص الدالة الحامضي تم قياس الأس الهيدروجيني pH في الترب الطبيعية المستعطلة في البحث على الطريقة المقدمة عن 
Journal of University of Babylon for Engineering Sciences, Vol. (26), No. (7): 2018.

Dispersive Soils of Special tests ثالثا: الفحوص الخاصة بالترب المشتية 1- فصص المكثاف المزدوج The Double Hydrometer Test تم إجراء هذا الفحص بالاعتماد على الطريقة المقترحة من قبل.[1] و واجري الفحص بطريقتين الأولى باستخدام المادة المشتتة (Dispersive agent) ويتم مزج التربة والماء بواسطة الخلاط الكهربائي ولمدة (15) دقيقة ، و الطريقة الثانية يجرى الفحص بدون استخدام المادة المشتتة و لا الخلاط الكهربائي ، ثم يتم رسم

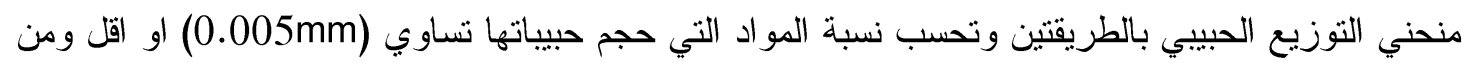
المعادلة التالية نحسب نسبة التشتت (Dispersion Percent) في التربة.

Dispersion $\%=\frac{\text { Finer than }(0.005 \mathrm{~mm})(\text { Untreated }) \%}{\text { Finer than }(0.005 \mathrm{~mm}) \text { in hydrometer test } \%}$

ويتم تصنيف التربة بهذه الطريقة (فحص المكثاف المزدوج) الثكل (1) من قبل [1] حسب الجدول التالي:

\begin{tabular}{|c|c|}
\hline Dispersion $\%$ & Classification \\
\hline$\% 0-\mathbf{3 5} \%$ & Non - Dispersive \\
\hline $\mathbf{3 5 \%}-\mathbf{5 0 \%}$ & Intermediate Dispersive \\
\hline$>\mathbf{5 0} \%$ & Highly Dispersive \\
\hline
\end{tabular}

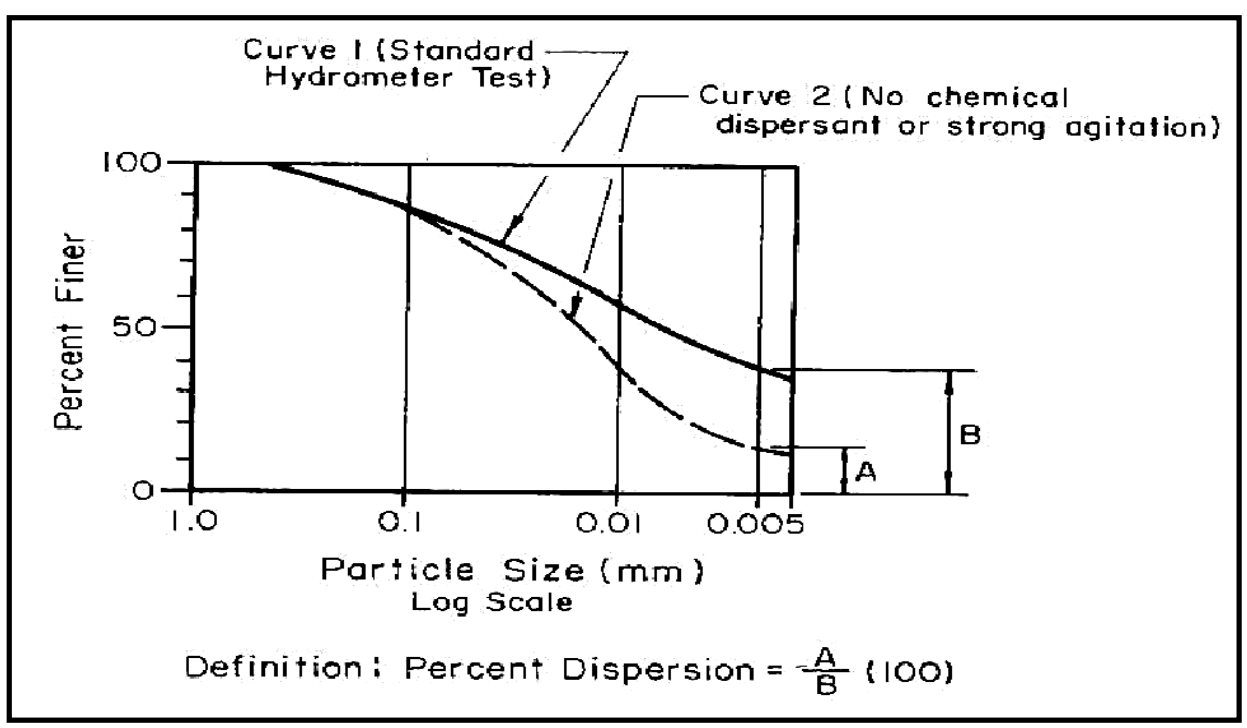

[1] شكل (1) منحني التدرج الحبيبي لفحص المكثاف المزدوج (Double Hydrometer Test) 
Journal of University of Babylon for Engineering Sciences, Vol. (26), No. (7): 2018.

Crumb test فحص الفتاتة

تم استخدام هذا الفحص في الحقل في بعض السدود المنهارة في استراليا وأمريكا، ويعتبر من أسرع

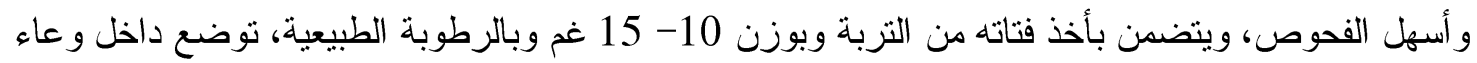
بحجم 150 مل تقريبا مملوء بالماء المقطر ثم يلاحظ ميل حبيبات التربة الى التشتت بعد (10-5 دقائق) وتصنف حالة التربة وعكورة الماء بعد (10دقائق)، كما مبين باللوحة رقم (2) وتصنف التربة حسب [1] كما بلاه

Grade 1 -1 لا يوجد تفاعل ولا عكوره في الماء اذ تترسب التربة في قاعدة البيكر. Grade 2 -2

Grade 3 -3 Grade 4 -4 انتشار لحبيبات التربة وحدوث تفاعل قوي مع تكون عو الق وتعكر بالماء.

The Slackening Test

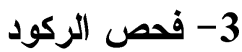

تم إجر اء هذا الفحص بعد تطوير فحص الفتاتة من قبل [ [15 وبين إن مقياس النتشت في فحص

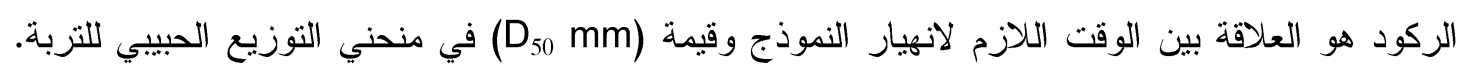

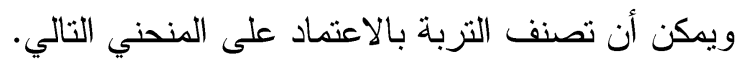

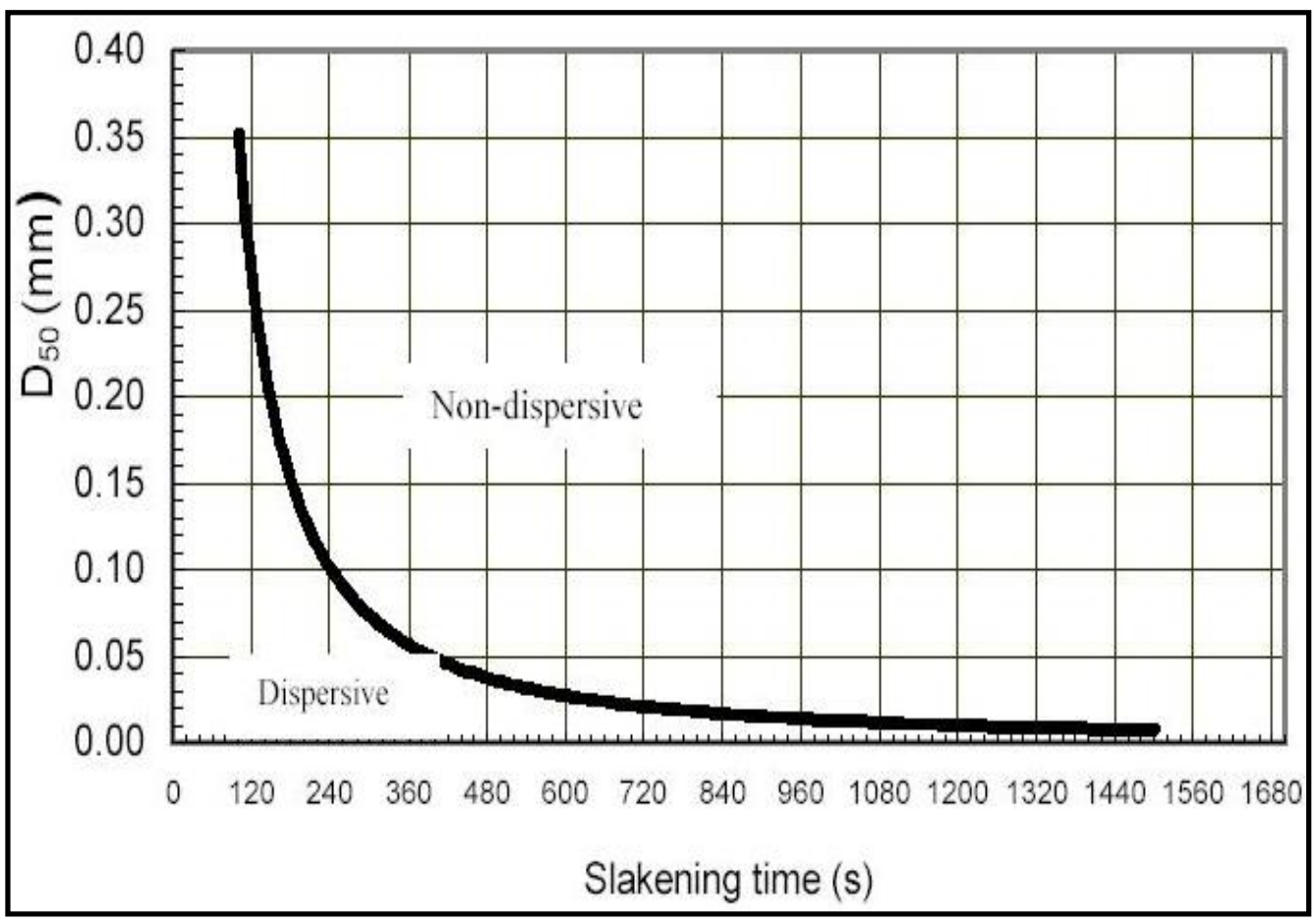

[15].Slackening test شكل (2) منحني تصنيف التربة باستخدام فحص الركود 
Journal of University of Babylon for Engineering Sciences, Vol. (26), No. (7): 2018.

Soluble Salts in pore water الأملاح الأبة في ماء المسام

تم إجراء هذا الفحص حسب ما ورد في قسم الزراعة للولايات المتحدة ضمن تشخيص وتحسين

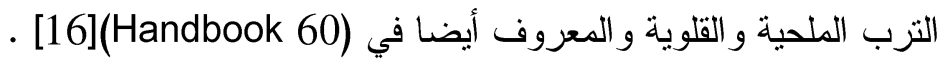

تم حساب مجموع الأملاح الذائبة (TDS) (الصوديوم، البوتاسيوم، المغنيسيوم، الكالسيوم) بوحدة الملي

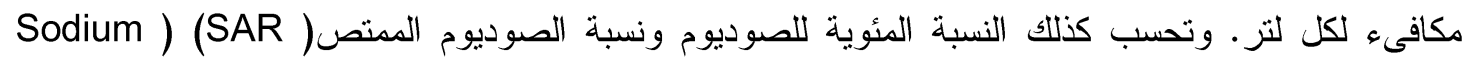
(absorption ratio

$\mathrm{Na} \%=(\mathrm{Na} / \mathrm{TDS}) * 100=(\mathrm{Na} / \mathrm{Ca}+\mathrm{Mg}+\mathrm{Na}+\mathrm{K}) * 100$

$\mathrm{TDS}=\mathrm{Ca}+\mathrm{Mg}+\mathrm{Na}+\mathrm{K}$

$\mathrm{SAR}=\mathrm{Na} /(0.5(\mathrm{Ca}+\mathrm{Mg})) \mathbf{1 / 2}$

ولغرض تصنيف التزبة يستخدم المنحني المقترح من قبل [1] و المبين بالثكل التالي

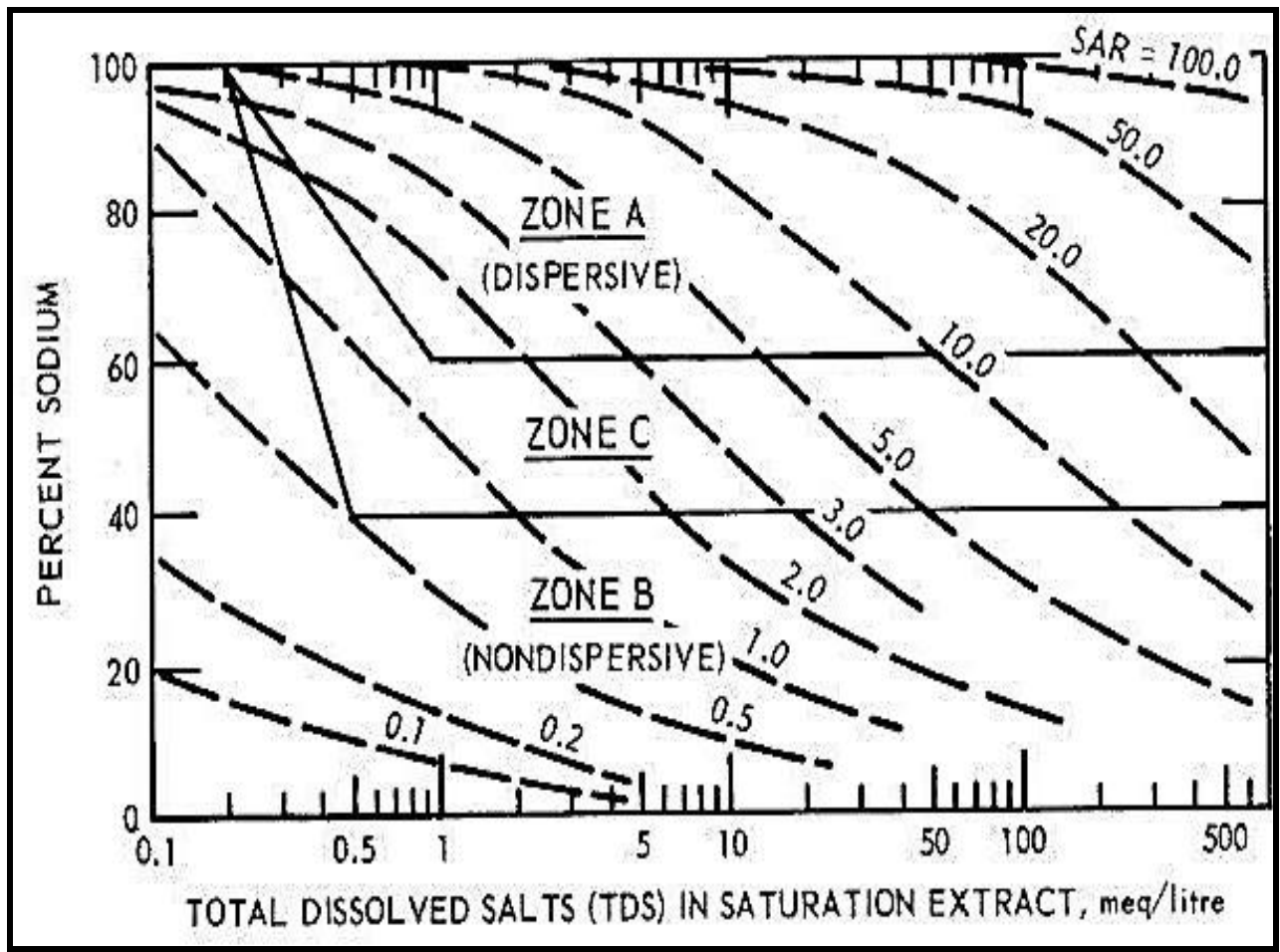

شكل (3) العلاقة بين الأملاح الذائبة الكلية (TDS) ونسبة الصوديوم وتثتت التربة[1] ـ

Results and discussion النتائج والمناقشة

اولا - خواص الترب الطبيعية

1-الخو اص الاليلية والفيزيائية والكيميائية

يبين الجدول (1) نتائج الخواص الدليلية والفيزيائية و الكيميائية للترب في منطقة الدراسة، حيث أظهرت الفحوصات الدليلية إن حد السيولة للترب يتغير بشكل تدريجي بسيط، وان معامل اللدونة يتغير من

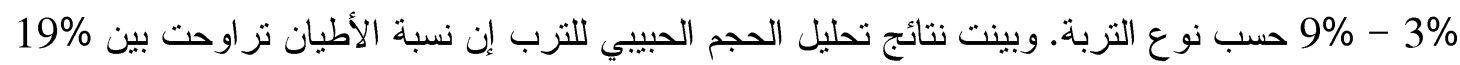


Journal of University of Babylon for Engineering Sciences, Vol. (26), No. (7): 2018.

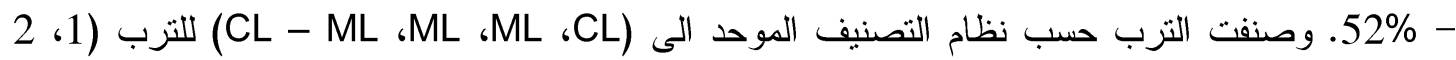
3، 4) على التو الي. أما نسبة الأملاح الذائبة (T.S.S) تراوحت للترب بين (1.26\% - 12\%).

جدول (1) يبين الخواص ألاليليه و الفيزيائية و الكيميائية للترب

\begin{tabular}{|c|c|c|c|c|c|c|}
\hline 4 & 3 & 2 & 1 & \multicolumn{2}{|c|}{ نوع التربة } & $ت$ \\
\hline الهاشمية & 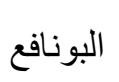 & 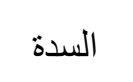 & المسيب/الخض & \multicolumn{2}{|c|}{ المنطقة } & 1 \\
\hline 2.71 & 2.72 & 2.73 & 2.75 & \multicolumn{2}{|c|}{ Specific Gravity(Gs) } & \\
\hline 27 & 26 & 29 & 30 & $\%$ L.L & \multirow{3}{*}{$\begin{array}{l}\text { Atterberg } \\
\text { Limits }\end{array}$} & \\
\hline 21 & 23 & 25 & 21 & $\%$ p.L & & \\
\hline 6 & 3 & 4 & 9 & $\%$ p.I & & 5 \\
\hline 4 & 7.5 & 5 & 2.5 & $\%$ sand & \multirow{3}{*}{$\begin{array}{l}\text { Grain size } \\
\text { of Soil }\end{array}$} & 6 \\
\hline 44 & 73.5 & 51 & 58.5 & $\%$ Silt & & \\
\hline 52 & 19 & 44 & 39 & $\%$ Clay & & \\
\hline 1.81 & 1.87 & 1.835 & 1.788 & $\begin{array}{c}\text { Max. } \\
\text { Dry } \\
\text { density }\end{array}$ & \multirow[t]{2}{*}{$\begin{array}{c}\text { Compactio } \\
n \\
\text { properties }\end{array}$} & 7 \\
\hline 13.6 & 11.5 & 15.1 & 14.6 & $\begin{array}{l}\text { Opt. } \\
\text { M.C }\end{array}$ & & \\
\hline 7.7 & 7.6 & 8.2 & 8.1 & \multicolumn{2}{|c|}{$\mathrm{PH}$} & 8 \\
\hline 1.99 & 2.24 & 2.77 & 2.98 & \multirow{2}{*}{\multicolumn{2}{|c|}{$\frac{\% \mathrm{SO} 3}{\% \mathrm{~T} . \mathrm{S} . \mathrm{S}}$}} & 9 \\
\hline 8.16 & 12 & 1.26 & 11.3 & & & 10 \\
\hline 4.27 & 4.92 & 5.95 & 6.407 & \multicolumn{2}{|c|}{ \%Gypsum } & 11 \\
\hline 0.0044 & 0.014 & 0.0085 & 0.0075 & \multicolumn{2}{|c|}{$\mathrm{D}_{50}$} & 12 \\
\hline CL-ML & ML & ML & CL & \multicolumn{2}{|c|}{$\begin{array}{c}\text { Unified Classification } \\
\text { System }\end{array}$} & 13 \\
\hline
\end{tabular}

ثانيا - خواص تميز الترب المشتتة

1- فص المكثاف المزدوج The Double Hydrometer Test

يبين الجدول رقم (2) و الإشكال (4 ، 5 ، 6 ،7) نتائج فحص التحليل الحجمي الحبيبي بالمكثــاف

المزدوج ودلت النتائج بعد تصنيف الترب حسب الطريقة المتبعة من قبل [1].

على ان نربة الخضر ونربة البونافع (1، 3) كانت (متوسطة التشتت Intermediate Dispersive)

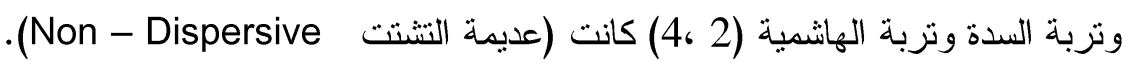


Journal of University of Babylon for Engineering Sciences, Vol. (26), No. (7): 2018.

جدول (2) يبين نتائج فحص المكثاف المزدوج للترب

\begin{tabular}{|c|c|c|c|c|}
\hline التصنيف & $\begin{array}{c}\text { التشتت } \\
\text { \% }\end{array}$ & نسبة المواد التي حجم ألغيباتها اقل أو تساوي & 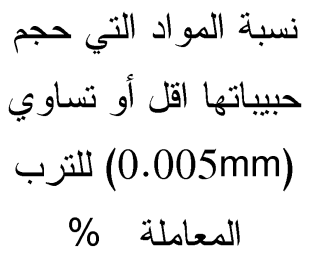 & نوع التربة \\
\hline $\begin{array}{l}\text { Intermediate } \\
\text { Dispersive }\end{array}$ & $48.7 \%$ & 19 & 39 & 1- الخضر \\
\hline $\begin{array}{c}\text { Non - } \\
\text { Dispersive }\end{array}$ & $25.5 \%$ & 11 & 43 & 2- السدة \\
\hline $\begin{array}{l}\text { Intermediate } \\
\text { Dispersive }\end{array}$ & $50 \%$ & 10 & 20 & 3- البونافع \\
\hline $\begin{array}{c}\text { Non - } \\
\text { Dispersive }\end{array}$ & $18 \%$ & 9 & 50 & 4- الهاشمية \\
\hline
\end{tabular}
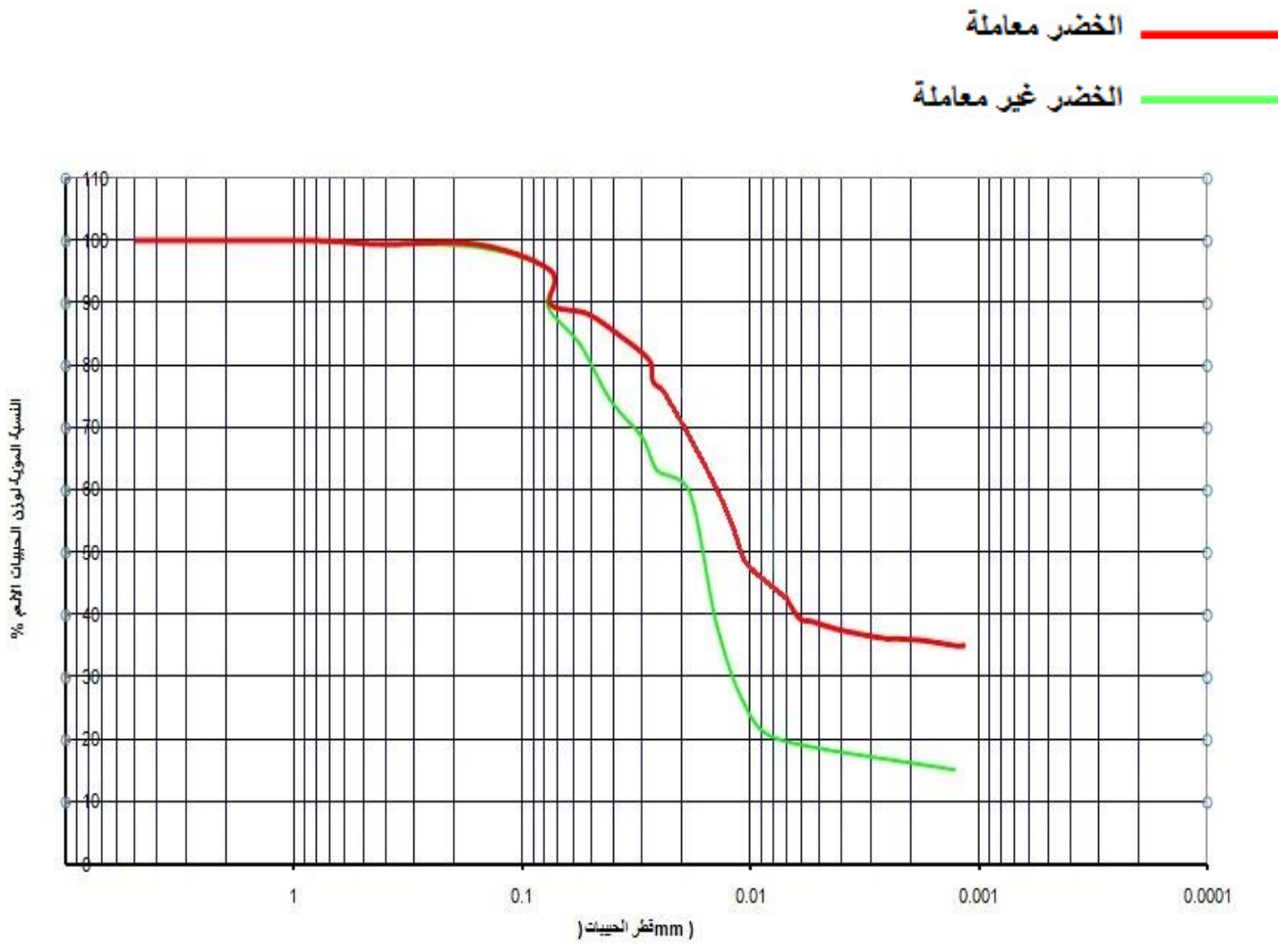

الثكل (4) يبين التحليل ألحجمي الحبيبي لفحص المكثاف المزدوج لتربة الخضر معاملة وغير معاملة 
Journal of University of Babylon for Engineering Sciences, Vol. (26), No. (7): 2018.

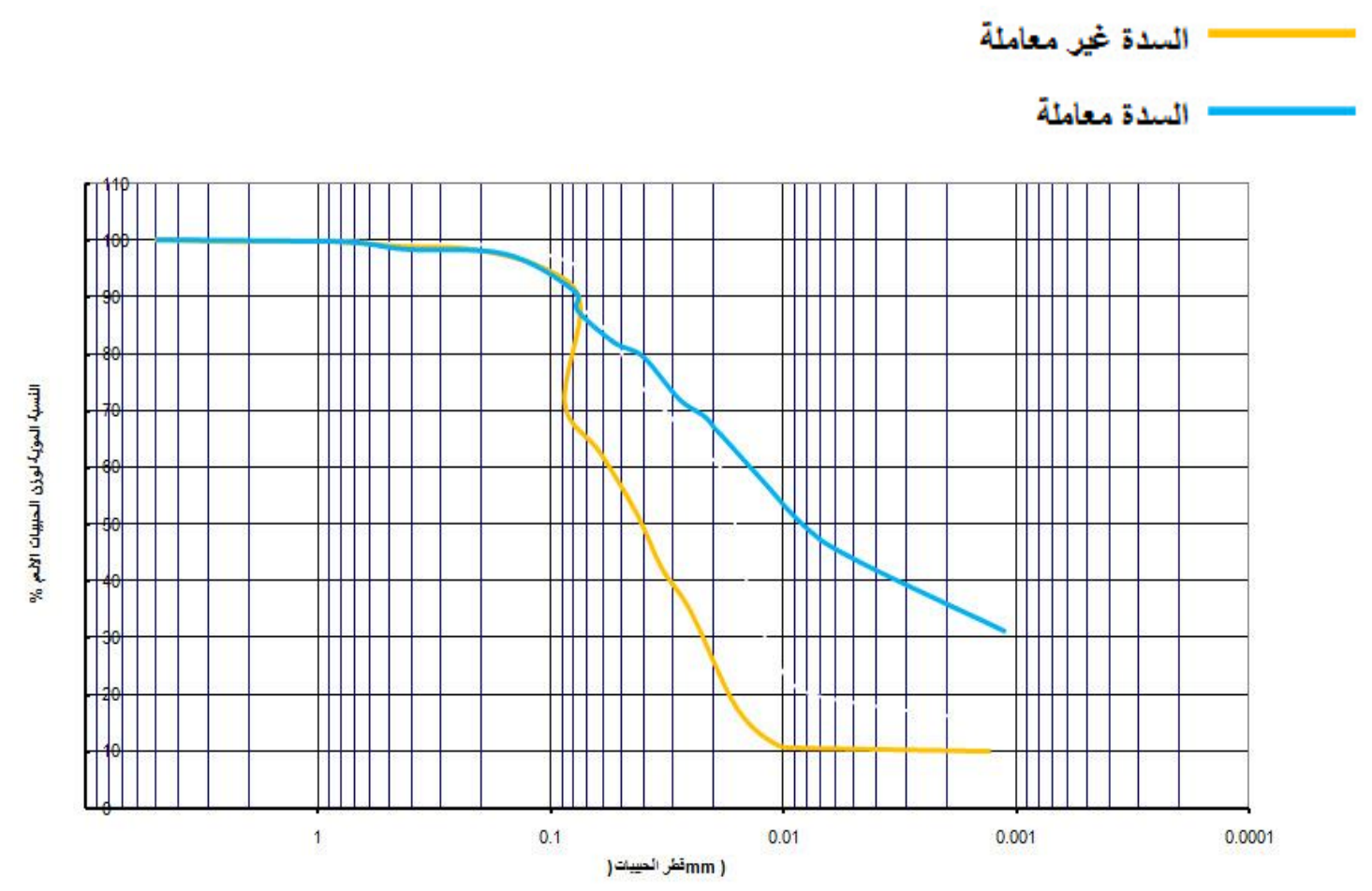

الثكل (5) يبين التحليل ألحجمي الحبيبي لفحص المكثاف المزدوج لتربة السدة معاملة وغير معاملة
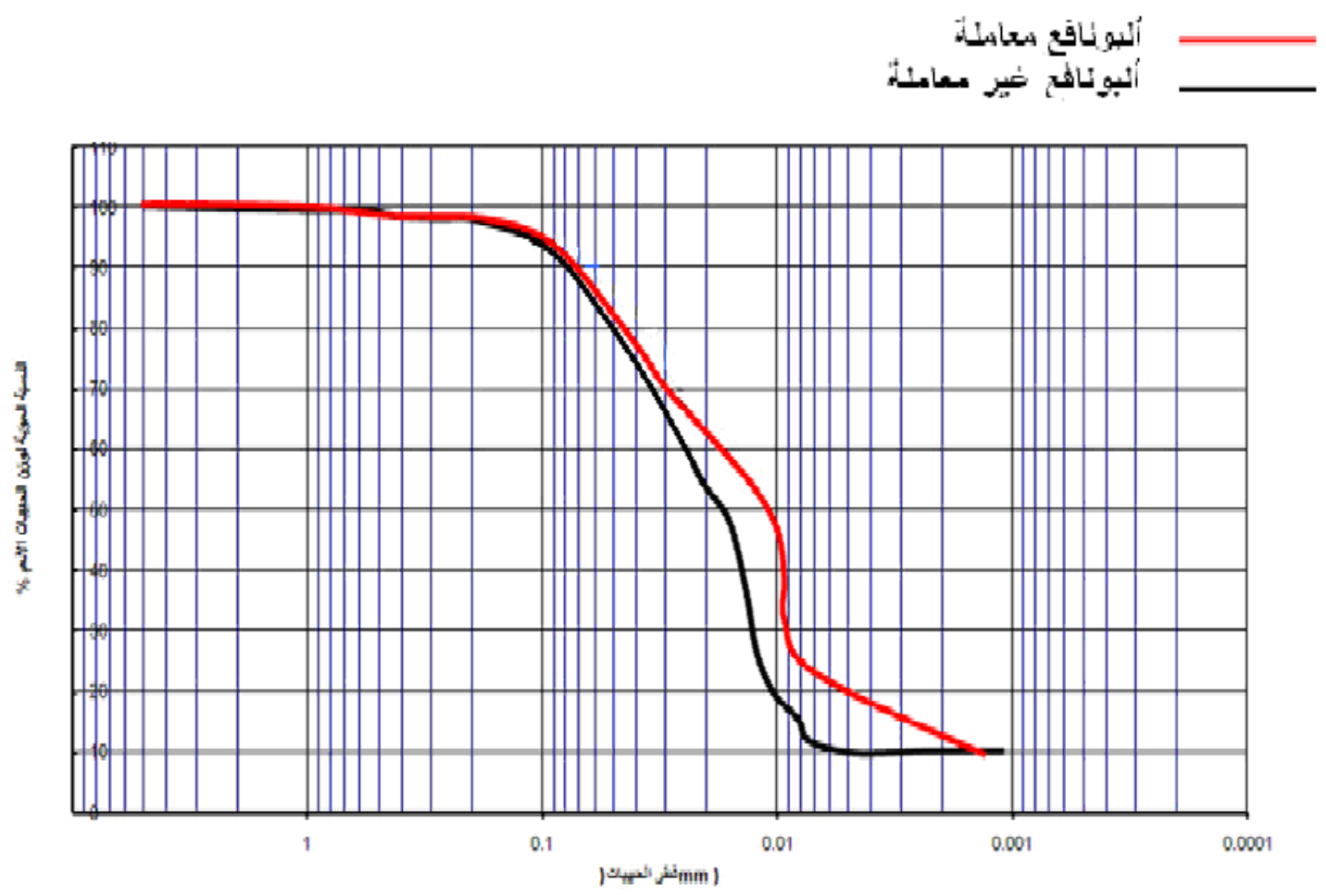

الثكل (6) يبين التحليل ألحجمي الحبيبي لفحص المكثاف المزدوج لتربة البونافع معاملة وغير معاملة 
Journal of University of Babylon for Engineering Sciences, Vol. (26), No. (7): 2018.

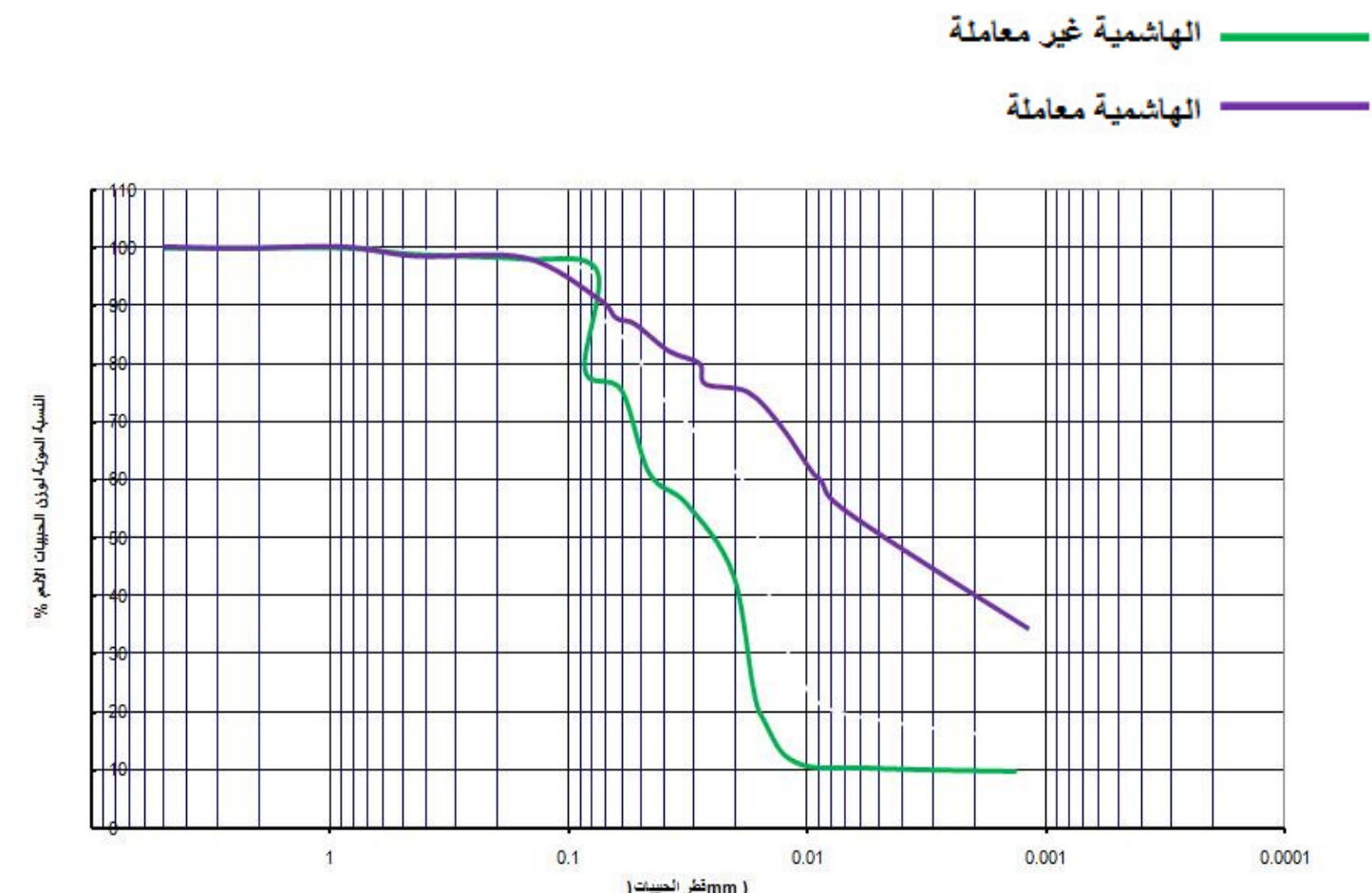

الثكل (7) يبين التحليل ألحجمي الحبيبي لفحص المكثاف المزدوج لتربة الهاثمية معاملة وغير معاملة

\section{Crumb test فصص الفتاتة}

تم إجر اء فحص الفتاتة حسب الطريقة المذكورة سابقا وتم تصنيف التزب حسب طريقة [1]كانت نتائج التصنيف مايلي تربة موقع السدة تصنف 2 Grade أما ترب مواقع (الخضر، البونافع، الهانثية) وجدت إنها Grade 3.

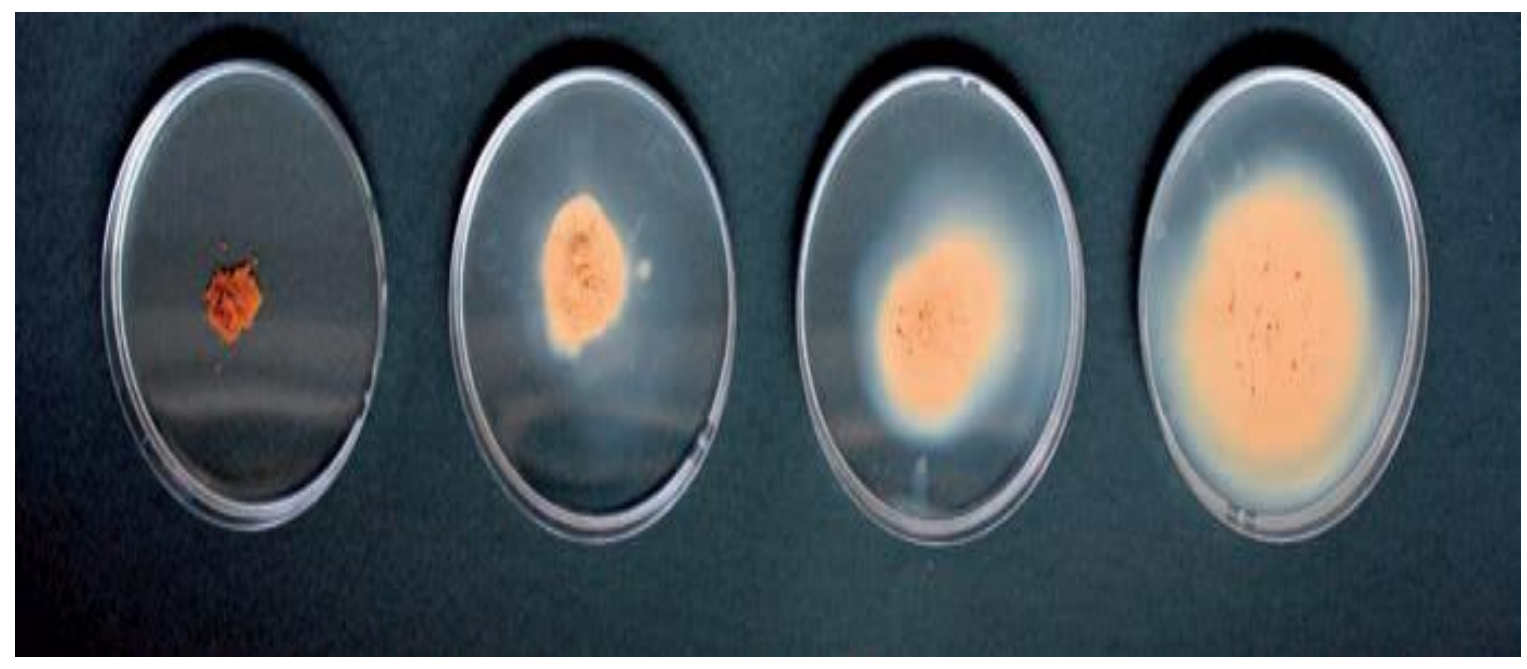

Grade 1

Grade 2

Grade 3

Grade 4

لوحة رقم (2) تبين فحص الفتاتة (Crumb test) 
Journal of University of Babylon for Engineering Sciences, Vol. (26), No. (7): 2018.

\section{The Slackening Test فحص الركود}

يبين الجدول (3) قيم D5 و الوقت اللازم لانهيار النماذج و الثكل (8) يبين منحني تمييز وتصنيف هذه

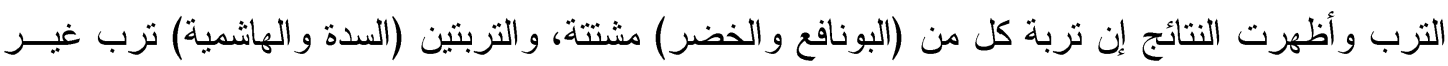

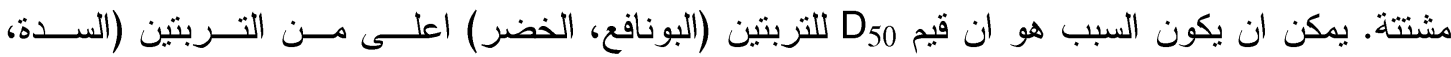

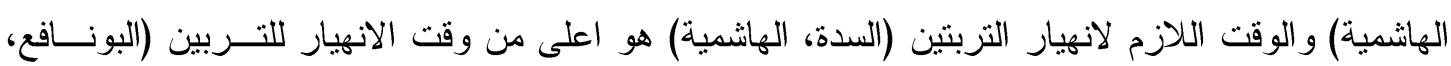

جدول (3) يبين نتائج فحص الركود (الوقت اللازم لاتهيار النموذج وقيم (D5) للترب (1،2، 3، 4)

\begin{tabular}{|c|c|c|}
\hline D50 mm & وقت انهيار النموذج للترب بال ثاتية & نوع التربة \\
\hline 0.012 & 680 & 1- 1- 1الخضر \\
\hline 0.0085 & 1690 & 2- 2- السدة \\
\hline 0.013 & 710 & 3 -البونافع \\
\hline 0.0044 & 1640 & 4-الهاشمية \\
\hline
\end{tabular}


Journal of University of Babylon for Engineering Sciences, Vol. (26), No. (7): 2018.

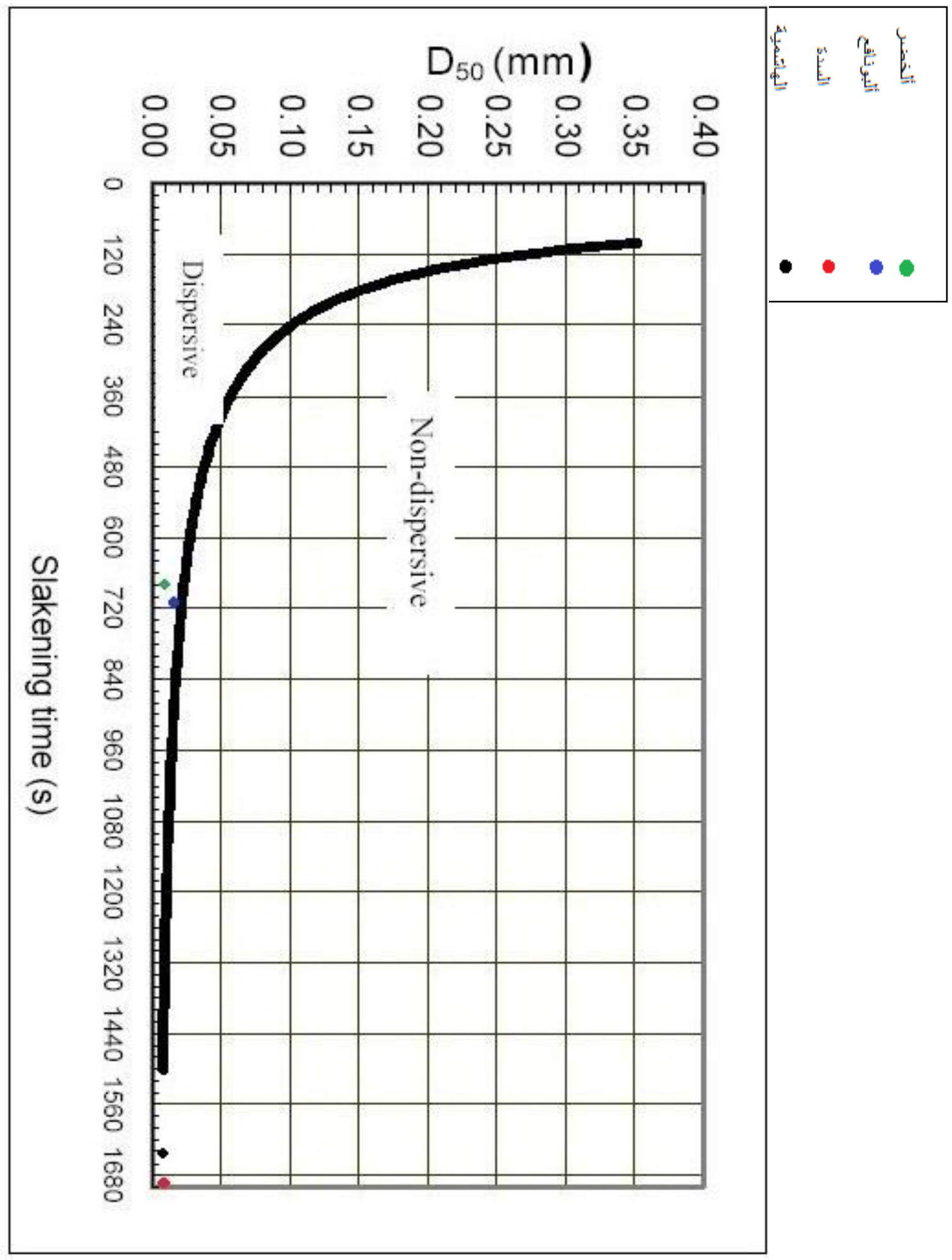

ألثكل (8) يبين منحني تصنيف الترب (1،1،2،34) لفحص الركود Slackening. 
Journal of University of Babylon for Engineering Sciences, Vol. (26), No. (7): 2018.

Soluble Salts in pore water الأملاح الأببة في ماء المسام تم حساب قيم كل من نسبة الصوديوم Na\% ومجموع الأملاح الذائبة الكلية (TDS) ونسبة الصوديوم الممتص (SAR) بوحدة الملي مكافىء لكل لتر كما مبين بالجدول (4) و استخدام البيانات و الثكل (9) الـــي

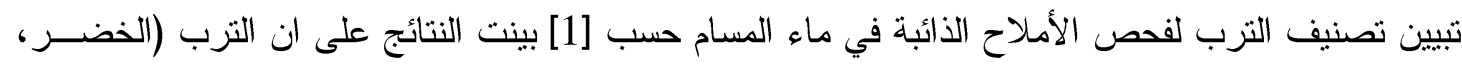

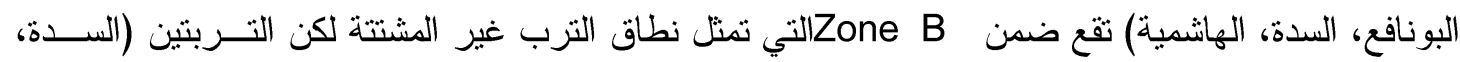

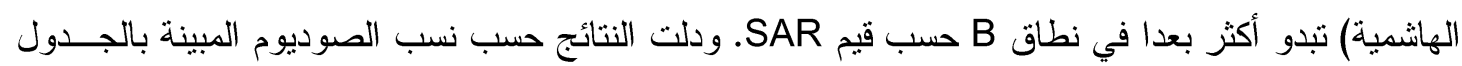
ان الترب (البونافع، الخضر ، السدة) مشتتة وان تربة (الهاثمية) تعتبر نربة غير مشتتة. جدول (4) يبين نتائج فحص الأملاح الأئبة في ماء المسام

\begin{tabular}{|c|c|c|c|c|}
\hline الهاشمية & السدة & البونافع & الخضر & التربة \\
\hline 0.39 & 0.180 & 0.75 & 0.65 & $\mathrm{~K}+\quad \mathrm{meq} / \mathrm{L}$ \\
\hline 2.53 & 1.11 & 14.18 & 11.4 & $\mathrm{Na}+\mathrm{meq} / \mathrm{L}$ \\
\hline 17 & 26 & 22 & 25.91 & $\mathrm{Ca}++\mathrm{meq} / \mathrm{L}$ \\
\hline 13.5 & 6.7 & 20 & 14.38 & $\mathbf{M g}++\quad \mathrm{meq} / \mathrm{L}$ \\
\hline 33.42 & 33.9 & 56.93 & 52.34 & TDS $\mathrm{meq} / \mathrm{L}$ \\
\hline 8.00 & 4.00 & 25 & 22 & $\mathrm{Na} \%$ \\
\hline 0.65 & 0.28 & 3.19 & 2.54 & $\mathrm{meq} / \mathrm{L}$ \\
\hline
\end{tabular}

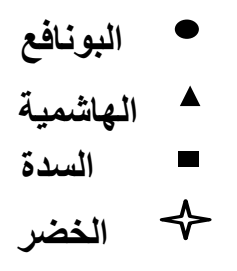

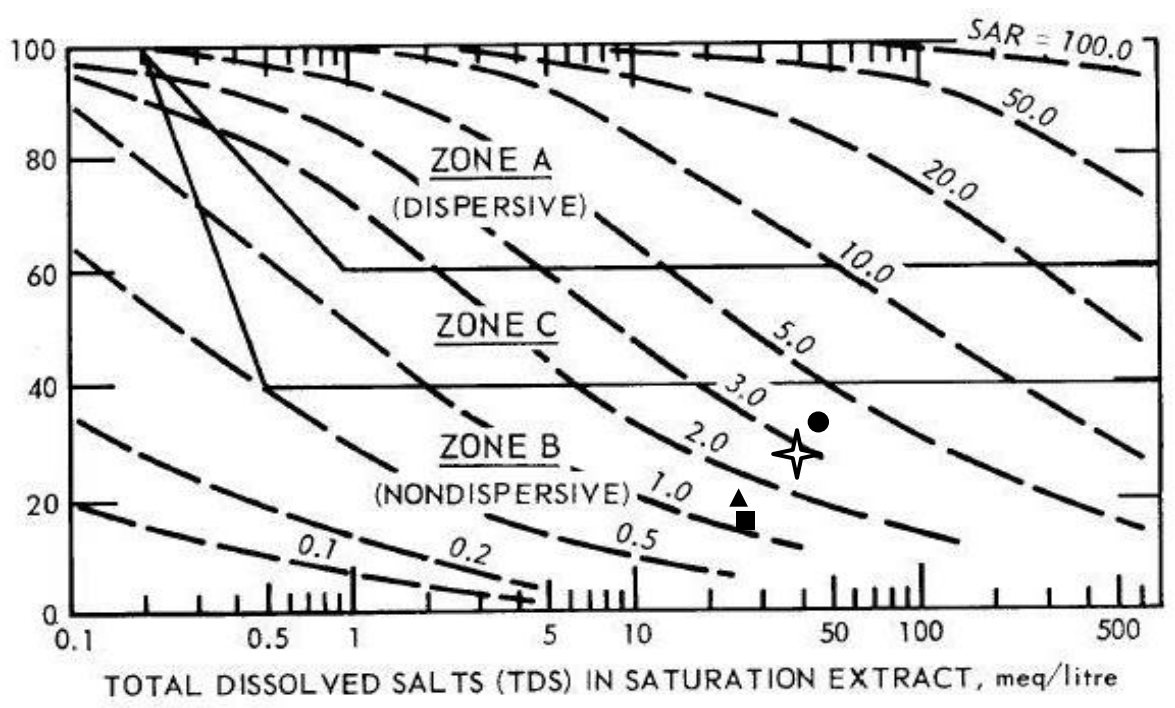

الثكل (9) تبيين تصنيف الترب لفصص الأملاح الذائبة في ماء المسام 


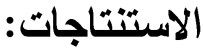

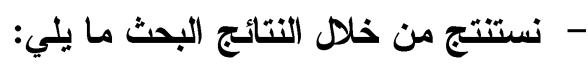

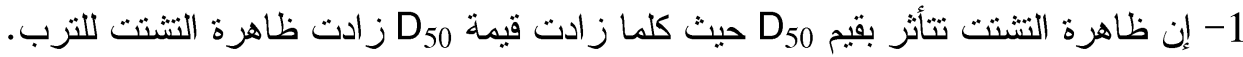

2- إن طريقة فحص المكثاف المزدوج للترب أعطت نتائج جيدة بسبب ان الترب المستخدمة في البحث هـي

$$
\text { ترب ليست جبسيه. }
$$

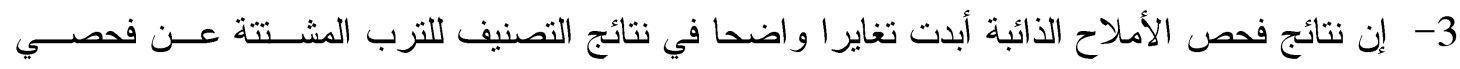

$$
\text { الركود و المكثاف المزدوج و هذا يعود إلى محتوى الترب من المكونات المعدنية و الكيميائية. }
$$

4- ان ظاهرة التثتت تتأثز بقيم دليل اللدونة للترب I.P، إذ إنها كلما قلت قيم I.P ازدادت قابلية التربة على

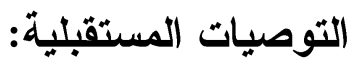

1- نوصي بدر اسة ظاهرة النتنت للترب في مناطق أخرى من محافظات الفرات الأوسط وبأعماق مختلفة.

2- نوصي بدر اسة استعمال بعض المو اد الكيميائية (الاسمنت، النورة المطفأة) لمعالجة ظاهرة التشتت للترب

المشتنة.

3- نوصي بوضع مو اصفات قياسية خاصة لظاهرة التشتت للترب.

\section{References}

[1] Sherard, J. L., Dunnigan, I. P., and Decker, R. S., "Identification and Nature of Dispersive Soils," Journal of geotechnical engineering division, Vol .102, No .1Gt4, pp.287 -301, 1976.

[2] Davies, S., and Lacey, A.,"Identifying Dispersive Soils" Department of Agriculture and Food, 2009. http:// www.agric.wa.gov.au

[3] Australian Center For Mining Environmental Research,"Identification And Management Of Dispersive Soil", Kenmore Qld 4069, Australia, 2004.

[4] Mc Daniel TN And Decker ,A. M.,"Dispersive Soil Problem At Los Esteros Dam" Journal Of Geotechnical Engineering division ,Vol .105 ,No .GT4 .Sep .,PP .10271029, 1979.

[5] Jane I., "Soil Classification Testing and Suitability", FSA, Irrigation, Page No. E7., 2001.

[6] Ali M. A., "Internal Erosion in Cores of Earth Dams" M.Sc, thesis, Civil engineering Department, College of engineering, University of mosul. 1978.

[8] Ismail F., Mohamed Z., and Mukri M.," A Study on the Mechanism Internal Erosion Resistance to Soil Slope Instability "Faculty of Civil EngineeringUniversiti Teknologi MARA Malaysia, 2008. http:// www.ejge.com/2008/Ppr 0809.pdf 
Journal of University of Babylon for Engineering Sciences, Vol. (26), No. (7): 2018.

[9] ASTM D 4318-84, "Standard Test Method for Liquid Limit, Plastic Limit, and Plasticity Index of Soils" Annual Book of ASTM Standards Vol, 04.08, 1986.

[10] ASTM D854-83, "Standard Test Method for Specific Gravity of Soils" Annual Book of ASTM Standards, Vol, 04. 08, 1986.

[11] ASTM D422-84, "Standard Method for Particle -Size Analysis of Soils", Annual Book, of ASTM Standards Vol, 04. 08, 1986.

[12] ASTM D698-78, "Standard Test Methods for Moisture-Density Relations of Soils and Soil Aggregate Mixture, Using $5.5 \mathrm{Ib}$ (2.49 kg) Rammer and 12-In. (305mm) Drop", Annual Book of ASTM Standards Vol, 04. 08, 1986.

[13] British Standards "Methods of Testing Soil for Civil Engineering Purposes". 1377: 1975.

[14] Eades J. L., and Grim R. E., "Reaction of Hydrates Lime with pure clay minerals in soil stabilization". Bulletin 262, Highway Research Board, Washington, Dc, 1960.

[15] Rahimi R.; Abbasi N. and Davarzani H., "Physical Dispersivity Phenomenon and Its Evaluation Criteria in Cohesionless Soils". $2^{\text {nd }}$ International conference on advances in soft soil engineering and technology, 2-4 July, Putrajaya, Malaysia, 2003.

[16] Richards L. A., "Diagnosis and Improvement of Saline and Alkali Soils," U.S. Dept. of Agriculture Handbook No. 60, U.S. Government Printing Office, Washington, D.C, 1954.

[7] موسى ، ز هير إسماعيل ، "در اسة التسرب التاكلي خلال الترب الجبسية و المعاملة بالنورة" رسـالة ماجستير ، كلية الهندسة ، القسم المدني ، جامعة الموصل، لدراسة 2005. 